\title{
Application of Digital Image Correlation (DIC) for tracking deformations of paintings on canvas
}

\author{
Marcin Malesa $^{* a}$, Krzysztof Malowany ${ }^{\mathrm{a}}$, Ludmiła Tymińska-Widmer ${ }^{\mathrm{b}}$, Ewa A. Kwiatkowska ${ }^{\mathrm{c}}$, \\ Małgorzata Kujawińska ${ }^{a}$, Bogumiła J. Rouba ${ }^{b}$, Piotr Targowski ${ }^{c}$ \\ ${ }^{a}$ Institute of Micromechanics and Photonics, Warsaw University of Technology, ul. Sw. Boboli 8, \\ 02-525 Warszawa, Poland \\ ${ }^{\mathrm{b}}$ Institute for the Study, Restoration and Conservation of Cultural Heritage, Nicolaus Copernicus \\ University, ul. Gagarina 7, 87-100 Torun, Poland \\ 'Institute of Physics, Nicolaus Copernicus University, ul. Grudziądzka 5, PL-87 100 Toruń, Poland
}

\begin{abstract}
A non-invasive and non-contact optical method for tracking overall and local deformations of canvas painting is presented. The technique was tested on a model painting on canvas with inhomogeneities introduced by infilling gaps, mending tears, and applying patches on the reverse of the canvas. The deformation of the sample was induced by changes of relative humidity. The feasibility of 3D Digital Image Correlation technique for evaluation of conservation methods is discussed.
\end{abstract}

Keywords: strain distribution testing, structural conservation-restoration of canvas, optical methods, artwork, easel painting

\section{INTRODUCTION}

Canvas paintings are complex, multilayer structures composed of hygroscopic materials of different properties and thus they are sensitive to cyclic changes of relative humidity in their surroundings. ${ }^{1-6}$ The components of a painting: canvas support, glue size, ground, oil paint and varnish react differently and cause inner stress to the structure. Therefore, during storage in unstable environment significant distortions of the picture plane but also cracking or cleavage can appear. In case of any discontinuities in the whole structure or in separate strata, these effects become more complicated and pronounced. These local discontinuities may be inherent to the painting technique or caused by a damage. Crackles, interlayer delamination, cuts, tears, gaps fall into the latter category, as well as improper repairs and patches which may introduce harmful stress concentrations into the structure.

Therefore when developing new conservation materials for local treatments such as consolidation, tear mending or gap filling, it is important to evaluate their compatibility to the original structures. Features like hygrostability and mechanical properties in changing climatic conditions are particularly important in such an assessment since the repairs should restore the continuity of the layers as completely as possible and should react the same way as the original structure in any condition.

The problem is significant when restored paintings are exhibited in museums, especially those placed in historical buildings. In such cases the strict requirements for climate control are in practice difficult to be fulfilled. Moreover, the recent attempt to reconsider and loosen the requirements for climate control in museums ${ }^{7,8}$ demands extended research into the actual sensitivity of different types of artworks and artefacts to environmental changes. For this purpose suitable measuring and monitoring systems need to be developed and applied.

Experiments reported in this paper concentrated on assessment of feasibility of the three dimensional Digital Image Correlation method ${ }^{9}$ (3D DIC) for materials studies focused on developing new methods for structural conservation of canvas paintings. Specifically, the application of the technique for measurements of local deformations of canvas painting models will be introduced. The perspectives for future works enabling the method to be applied for examination of real artworks in museum environment will be presented in conclusions.

*m.malesa@mchtr.pw.edu.pl; phone 48 222348635; fax +48 222348601

O3A: Optics for Arts, Architecture, and Archaeology III, edited by Luca Pezzati, Renzo Salimbeni, Proc. of SPIE Vol. 8084, 80840L · (c) 2011 SPIE · CCC code: 0277-786X/11/\$18 · doi: 10.1117/12.889452 


\section{METHODOLOGY}

Paintings on canvas are objects relatively flexible and considerably sensitive to deformations. To reveal discontinuities or inhomogeneities in the structure of a painting or to assess the compatibility of primary and added materials a method capable of tracking of local displacements against a background of significant overall surface deformation is required. Hence, such a method should combine a large field of view with a sub-millimetre resolution and accuracy in three dimensions. In case of painting canvases mounted on traditional wooden stretchers, out-of-plane deformation happens to be considerably high and can influence readings of the strain observed in plane. ${ }^{10}$ Therefore, it is essential to use a method capable of recording in-plane and out-of-plane displacements simultaneously within a reasonably wide range of displacements.

Most of the methods used for structural damage measurements in the conservation of the art works such as use of strain gauges or optical fibre sensors, holographic and electronic speckle pattern 2D interferometry (ESPI), photoelastic stress analysis, photogrammetry, thermography, ultrasonic and X-ray imaging do not satisfy these main requirements. ${ }^{11}$ Only in the recent account by Debashis and Young ${ }^{12}$ the simultaneous 3D interferometry in reported. Similarly, Optical Coherence Tomography (OCT) may be used for precise 3D tracking of the canvas deformation but it is point-wise only in a present version. ${ }^{10,13}$

On the contrary, the 3D DIC seems to meet these requirements well and provides some extra features like scalable fieldof-view (FOV), flexibility with data acquisition frequency, relatively cheap hardware configuration. ${ }^{9}$ The Digital Image Correlation is now widely used in the field of experimental mechanics, material engineering and monitoring of engineering structures. ${ }^{14,15}$ Recently it has been successfully applied in the field of conservation of art for strain monitoring in historic tapestries. ${ }^{16,17}$ The authors demonstrated the feasibility of the DIC method for non-contact fullfield quantitative analysis of three-dimensional displacement and in-plain strains in large textiles. Moreover, the method has been used for a long-term monitoring of textile deformations caused by fluctuations of climatic conditions in museum environment.

\section{EXPERIMENTAL}

\subsection{Digital Image Correlation}

The two-dimensional DIC (2D DIC) measurement procedure is very simple and it requires to capture a series of images of a tested object before and after a load (or during loading). The surface of the object however, must have a natural random texture or it has to be covered by a random (speckle) pattern before the measurements start. One of images of the series is chosen as a reference image for all consequent analyses. All images are divided into small rectangular regions (subsets) consisting of $\mathrm{N} \times \mathrm{N}$ pixels. Dimensions of the subsets are dependent on the quality of the random pattern on the measured object. They can vary from $7 \times 7$ pixels (conventionally) to $70 \times 70$ pixels and even more. The DIC algorithm is then tracking the position of each subset from the reference image in all other images of the series. Corresponding subsets are matched by finding the maximum of the normalized cross-correlation function coefficient. For each subset in-plane displacement vectors ( $\mathbf{U}$ and $\mathbf{V}$ ) are then calculated. Sub-pixel accuracy is achieved by sophisticated interpolation methods. The output data is provided as a set of displacement maps, which can be consequently used for strain calculation.

In 3D DIC used in the presented experiment, for each state of an object two images are registered simultaneously by two cameras viewing the object from slightly different directions (Fig. 1a). The DIC method combined with stereovision methods ${ }^{18}$ provides the maps of out-of-plane and in-plane displacements of and within an object which have occurred between acquisitions of images. ${ }^{9}$ The 3D DIC measurement procedure is presented in figure $1 \mathrm{~b}$.

For the 3D DIC setup (Fig. 2a) two AVT Stingray 2MPx (1624x1232 pixels) cameras equipped with 8mm Schneider Kreuznach lenses have been used. The setup was stiffly mounted on the same optical table as specimen, thus its mechanical stability relative to the specimen could be assumed. The FOV was $0.4 \mathrm{~m} \mathrm{x} 0.3 \mathrm{~m}$ and the estimated accuracy was $0.02 \mathrm{~mm}$. In order to ensure sufficient lighting conditions, the $650 \mathrm{~W}$ halogen lamp was additionally used. The measurements were hindered because of the reflexes on the front glass of the climate chamber. Reflexes were eliminated by optimizing the direction of illumination and black masking tape. Two cameras were capturing images simultaneously every 20 seconds. Total time of a single test was approximately $2.5 \mathrm{~h}$. Analysis were carried out with the commercial software VIC-3D. 
a

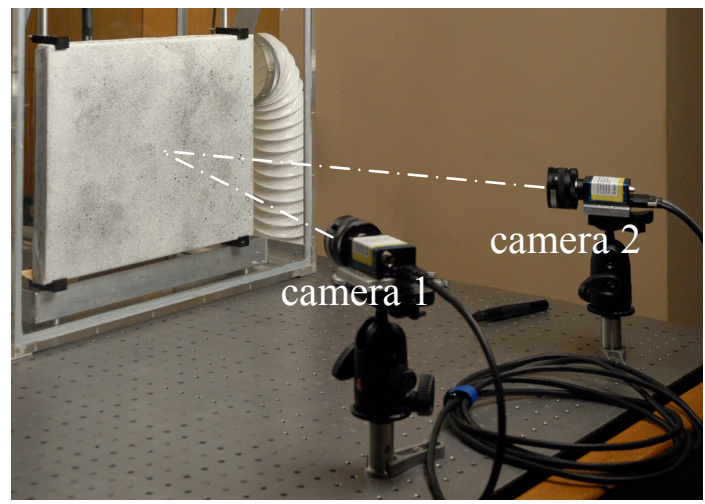

b

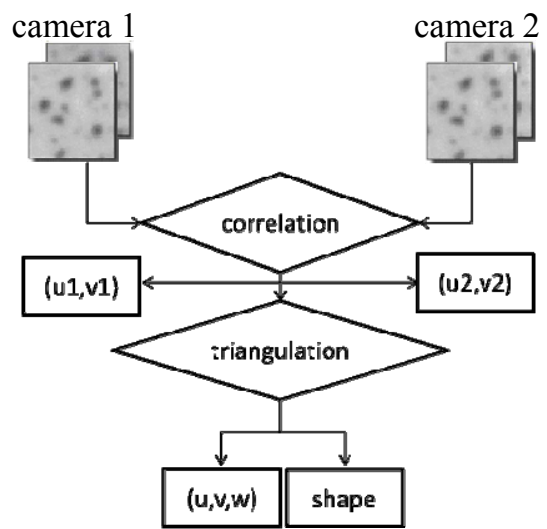

Figure 1. Three-dimensional Digital Image Correlation; a: set-up; b: data processing flow chart

\subsection{Model sample}

A model painting on canvas $40 \mathrm{~cm}$ wide and $30 \mathrm{~cm}$ high was used as the object under examination. In order to diminish the number of factors that could influence and complicate interpretation of the results of experiment, the sample was made of uniform, commercially primed fine plain weave canvas stretched over a keyed wooden stretcher with weft in the vertical direction. To create discontinuities in its structure four sets of regular circular gaps of various sizes ranging from 4 to $12 \mathrm{~mm}$ of diameter were made symmetrically through the stencil in all the four corners of the model according to the prepared template (Fig. 2a). Additionally two L-shaped cuts were made in the central part of the model. Each of the sets of gaps was filled in with traditional and experimental inserts, different in respect of structure, mechanical properties and sensitivity to climatic changes and thus the match to the surrounding original structure of the canvas painting (Fig. 2b). To allow image correlation a random speckle pattern was sprayed onto the face of the sample with a black ink (Fig. 3c).

a

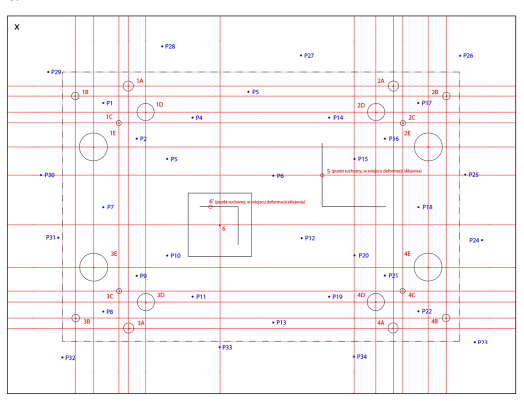

b

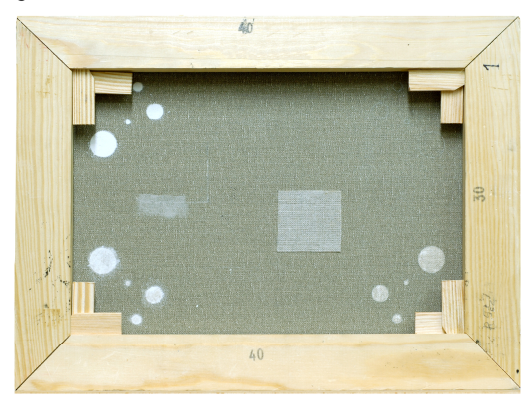

$\mathrm{c}$

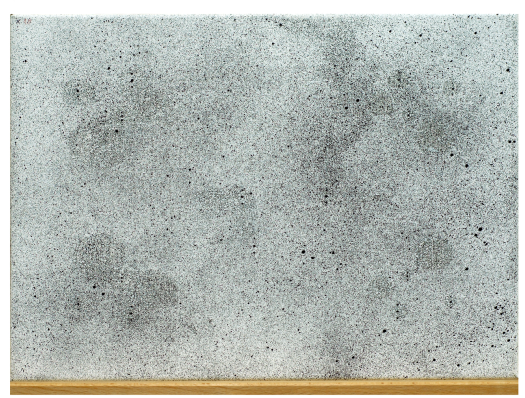

Figure 2. Model painting on canvas repaired with various methods; a: template showing positions of discontinuities introduced to the canvas and used further as a reference for analysis of the data extracted from DIC records; $b$ : reverse with inserts and patches; c: face of the painting with a random pattern

As an example of detailed analysis presented in Results section a cut butt-joined with dispersive adhesive (Osakryl + Winacet DP 50 in ratio 1:1 by weight) was chosen. An emulsive gesso (based on chalk, carboxymethylcellulose, polyvinyl alcohol, with plasticizers: Venetian turpentine and dammar in oil of turpentine) was used for infilling the ground. The repair was partially reinforced from the reverse with a rectangular piece of a flax tissue adhered with $3 \%$ carboxymethylcellulose (lap join). 


\subsection{Climate control chamber}

The sample was subjected to environmental stress caused by rapid changes of relative humidity in a custom designed airtight climate chamber. The chamber was connected with large diameter air ducts to a simple external set-up to control relative humidity level in the range from $30 \%$ to $75 \% \mathrm{RH}$. The parameters of temperature and $\mathrm{RH}$ inside the chamber were monitored and recorded with a HygroClip ${ }^{\circledR}$ S sensor from Rotronic (Switzerland).

\section{RESULTS}

During the experiment DIC data were collected every 20 seconds together with the relative humidity (RH) and temperature values. After processing, the displacement maps were correlated with humidity data and combined into video animations for convenient inspection. In Fig. 3 examples of such maps are given for 55 min of experiment, when the relative humidity reached its maximum value of $73 \%$. It is worthwhile to note that the in-plane displacement $(\mathrm{U}, \mathrm{V})$ are one order of magnitude lower than the displacement observed out of plane.
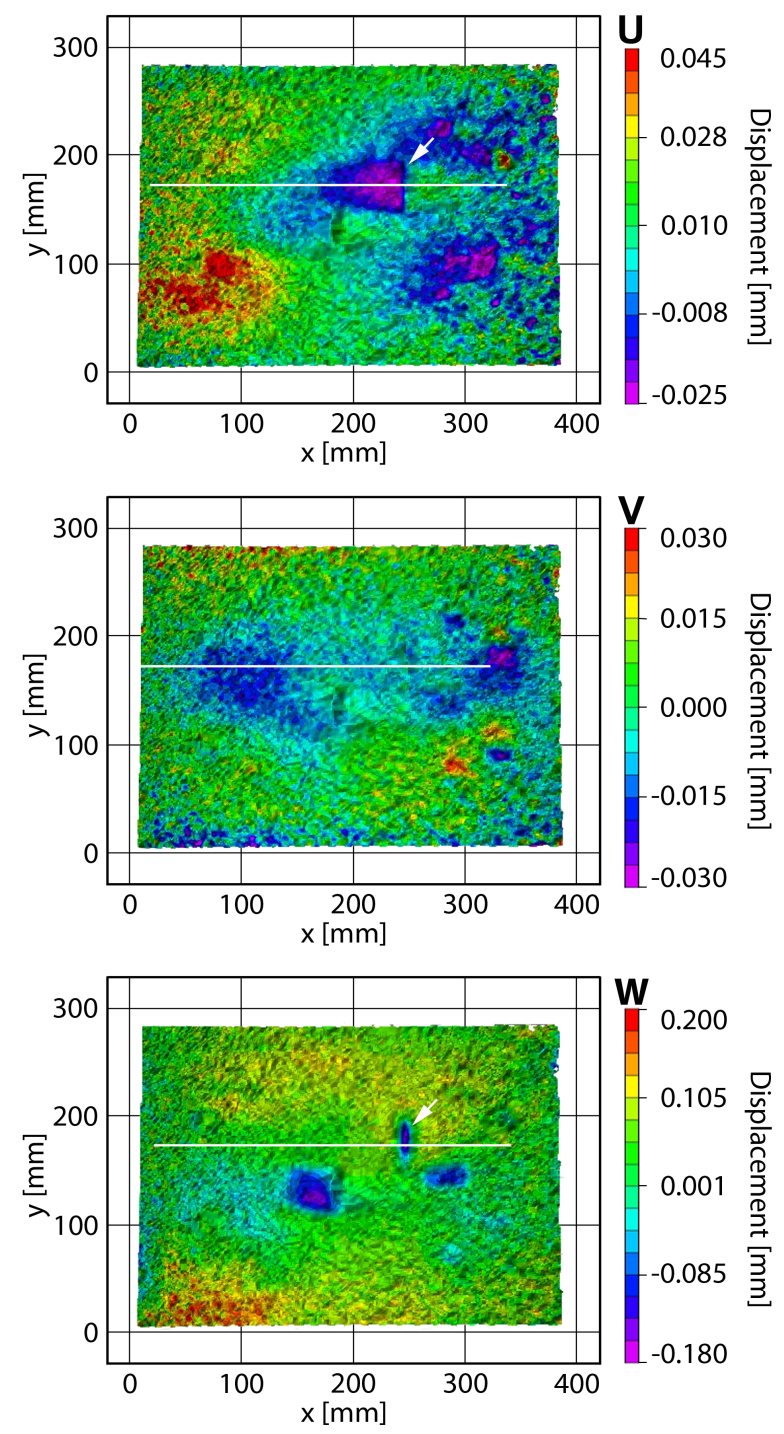

Figure 3. Relative displacement maps: $\mathrm{U}-$ in $\mathrm{x}$ direction, $\mathrm{V}-$ in y direction, $\mathrm{W}-$ in $\mathrm{z}$ direction at $73 \% \mathrm{RH}$. Displacements are colour-coded, separately for each map. White lines indicate position of a cross-section over the discontinuity (arrow) analysed in details in Figs 4 and 5 
Such images are very useful for qualitative inspection and observation of overall deformations. The behaviour observed in the figure 3 is typical for canvas paintings mounted over a quite stiff traditional wooden stretcher. The changes in the dimensions of canvas induced by variations of relative humidity result in immediate changes in stress and are observed as bulging and waving of the surface out of plane. As one can see from the figure, in-plane deformations $(\mathrm{U}, \mathrm{V})$ are different in warp (x - horizontal) and weft (y - vertical) directions. At the maximum of humidity, canvas displacements along warp treads are directed towards the centre of the picture. The behaviour in weft direction is more complicated: at the perimeters of the canvas movements are generally outward whereas in the centre two zones of strain in opposite directions are present. The out-of-plane (W) overall deformations are much more pronounced. Additionally, the local effects caused by discontinuities introduced to the structure of canvas are visible on $\mathrm{U}, \mathrm{V}, \mathrm{W}$ displacement maps in the form of regular displacements different in colour from the surrounding background (upper right and lower right corner of the sample). However, for their quantitative analysis another approach to data presentation suits better. In Fig. 4 displacements at points along a chosen line (marked as a white segment in Fig. 3.) located across the centre of a vertical cut butt-joined with synthetic adhesive are presented as a function of time. Such imaging of the data shows development of a very characteristic deformation in the area of the repair.
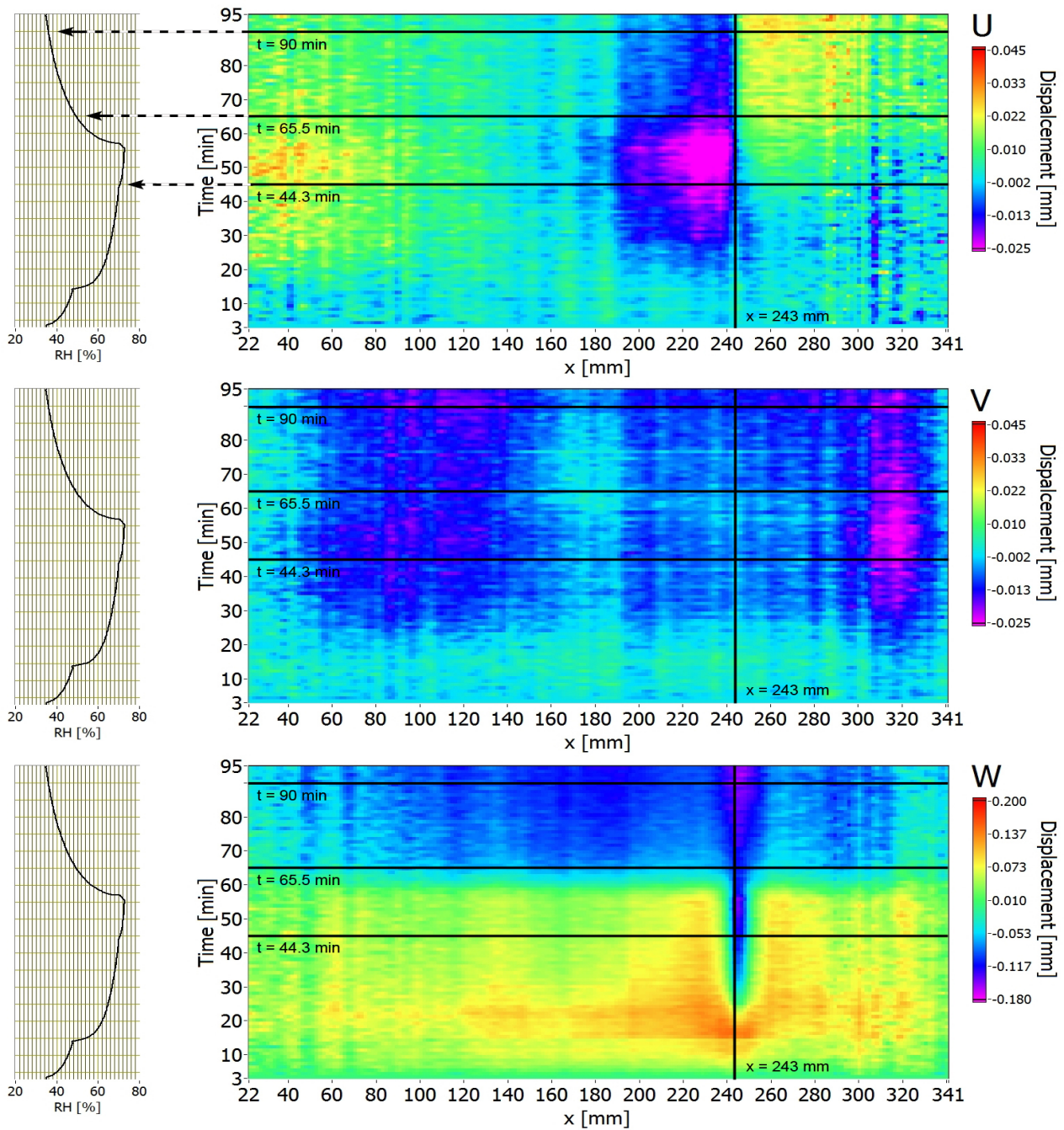

Figure 4. Relative displacements at points along a white line in Fig. $3(\mathrm{y}=171 \mathrm{~mm})$ shown as a function of time. Corresponding changes in relative humidity are given for reference. Horizontal and vertical black lines indicate locations of cross-sections presented at Fig. 5 and 6 respectively. 
Images in Figure 4 comprise more global information whereas figures 5 and 6 may be used for more precise, quantitative evaluation. In Fig. 5 displacements along the white line in Fig. 3 are shown for the chosen moments of time, while in Fig. 6 displacements in one point $(x=243 \mathrm{~mm}, \mathrm{y}=171 \mathrm{~mm})$ together with the concurrent relative humidity are shown as a function of time for a whole duration of the experiment.
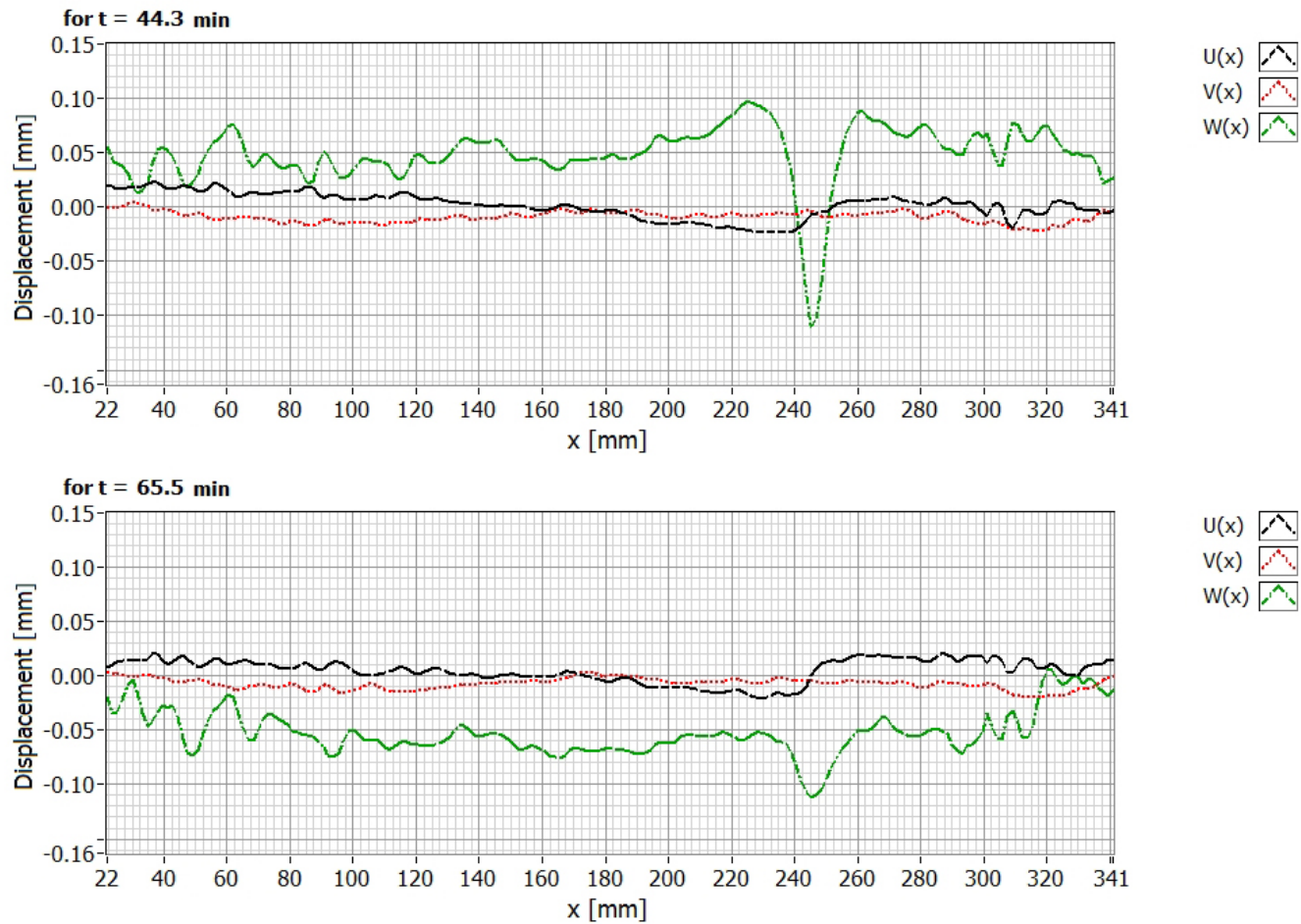

$\mathrm{u}(\mathrm{x}) \stackrel{\mathrm{A}}{\mathrm{A}}$

$\mathrm{V}(\mathrm{x})$

$w(x)$ in.

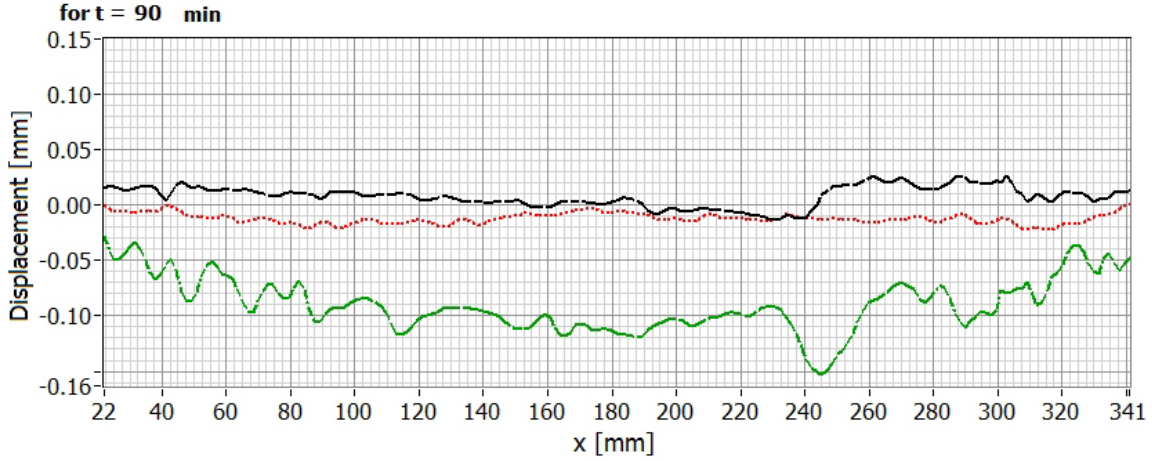

$\mathrm{U}(\mathrm{x}) \stackrel{\mathrm{A}}{\mathrm{A}}$

$\mathrm{v}(\mathrm{x}) \mathrm{No}_{0}$

$W(x)$

Figure 5. Relative displacements at $\mathrm{y}=171 \mathrm{~mm}$ shown for chosen moments in time after the beginning of the experiment $(\mathrm{t}=44.3 \mathrm{~min}$ at $\mathrm{RH}=70 \%, \mathrm{t}=65.5 \mathrm{~min}$ at $\mathrm{RH}=50 \%, \mathrm{t}=90.5 \mathrm{~min}$ at $\mathrm{RH}=36 \%)$.

From the Figure 4 one can read that distinct out-of-plane displacements (W) occur immediately with a variation of climatic conditions while in-plane deformations (U, V) are registered later (after c. 20 min.). It is worth to point out the effect of hysteresis: painting doesn't return to its original state when humidity comes back to its initial value. On the background of overall deformation of the canvas painting, the local behaviour of the surface in vicinity if the discontinuity can be analysed. The increase of humidity causes the elevation of the edges of a cut (located at $\mathrm{x}=243$ $\mathrm{mm}$ ) and then the process of disconnection of the join starts at $\mathrm{t} \approx 20 \mathrm{~min}$ (at $\mathrm{RH}=63 \%$ ). On the map of out-of-plane displacements (W) a crack appears distinctly. At the same time, as it is clearly visible on the map of U displacements (x direction), slow opening of the crack begins. The canvas on the left side of the crack crimps towards the centre of the 
painting whilst the on the right seems to be still. When the humidity reaches its maximum of $73 \% \mathrm{RH}$, the displacement of the edges of the crack develops in both directions. Then, during drying, deformation of the right side toward the edge of the painting dominates and rises constantly until the end of experiment. Concurrently the edges of the crack deform out of plane and bend backwards. The amplitudes of overall displacements during all the experiment can be read from the colour scale in Fig. 4 and directly from Figs 5 and 6.

Specifically, from the Fig. 6 it is evident that any rapid change of relative humidity $(t=3,14,57$ min.) causes an immediate out-of-plane reaction of the painting. It is also possible to define precisely the moment of failure of the gluejoin $(t=17 \mathrm{~min})$ as the point of reverse of the direction of out-of-plane deformation.

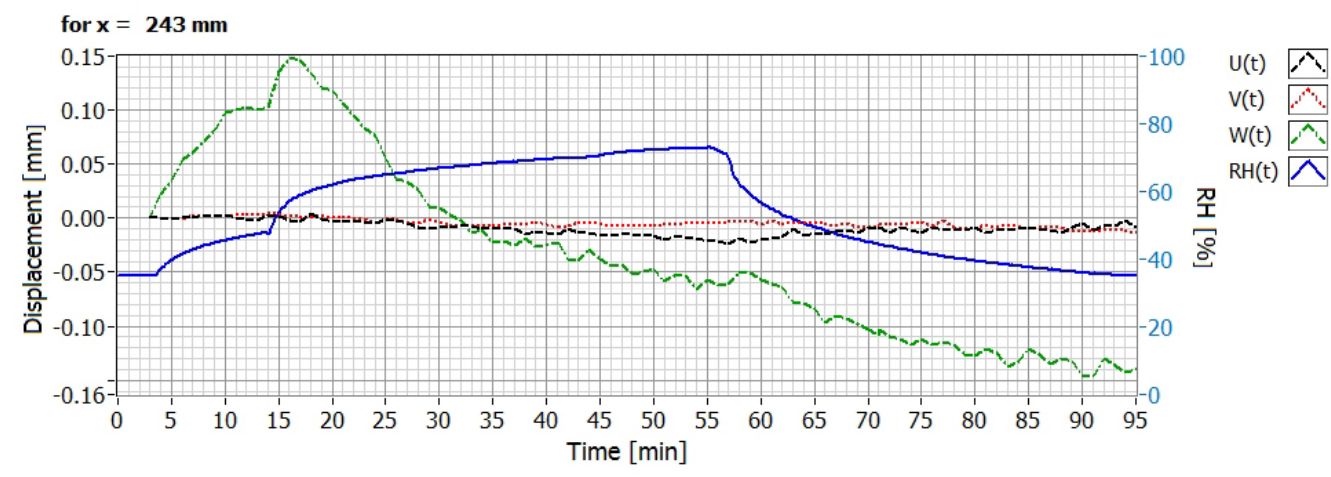

Figure 6. Displacements at a chosen point $(\mathrm{x}=243 \mathrm{~mm}, \mathrm{y}=171 \mathrm{~mm})$ as a function of time together with the relative humidity in the climate chamber.

\section{CONCLUSIONS}

Feasibility studies on 3D DIC method proved its suitability for canvas paintings measurements. The method is capable of detecting deformations: their location, range and shape and also their development in time. The results are unambiguous and their interpretation is straightforward. The registration of deformation is automatic, and made with at a high rate over a long period of time. Therefore this method may used for monitoring of processes with time resolution of single seconds. With the described technique it is possible to track quantitatively overall deformations of the whole canvas as well as local strains caused, in our case, by discontinuities introduced deliberately to the structure of canvas.

However, further research and readjustments of the set-up need to be undertaken in order to decrease uncertainties of the received data. Specifically, cameras with bigger resolution need to be used and consequently more precise calibration needs to be performed. It is expected that such improvement would extend a selection of detectable discontinuities in painting structure (e.g. cleavages, delaminations, crackles) and also would permit examination of larger variety of canvas supports with different hygrostability. In the presented experiment a random pattern was applied on the face of the sample. Such approach is possible in the case of materials studies since it is invasive although reversible. The usage of the DIC for examination of real artworks demands further studies that will specify certain features of the surface of the painting that may be sufficient as a random pattern for correlation. Consequently the parameters of the experimental setup and data analysis must be adjusted. It is expected that some painting techniques or irregular texture of canvas visible from under the paint layer can appear to provide a pattern sufficient enough to carry out experiments on real artworks.

\section{ACKNOWLEDGEMENTS}

The financial support from the project "Health Monitoring and Lifetime Assessment of Structures" - MONIT POIG.0101.02-00-013/08-00 from the EU Structural Funds in Poland and a grant support from the Rector of Nicolaus Copernicus University are gratefully acknowledged. 


\section{REFERENCES}

[1] Mecklenburg, M. F., "The Structure of Canvas Supported Paintings", Preprints of the International Conference on Painting Conservation - Canvases: Behaviour, Deterioration and Treatment, 119-155 (2005).

[2] Mecklenburg, M. F., "Micro Climates and Moisture Induced Damage to Paintings", Conference on Micro Climates in Museums, 19-25 (2007).

[3] Mecklenburg, M. F., [Meccanismi di cedimento nei dipinti su tela: approcci per lo sviluppo di protocolli di consolidamento (Failure Mechanisms in Canvas Supported Paintings: Approaches for Developing Consolidation Protocol)], Il prato, Padova (2007).

[4] Rouba, B., "Die Leinwandstrukturanalyse und ihre Anwendung für Gemäldekonservierung", Restauratorenblätter $13,79-90$ (1992).

[5] Rouba, B. J., [Podobrazia płócienne w procesie konserwacji (Canvas Painting Supports in the Process of Conservation)], Wydawnictwo UMK, Toruń (2000).

[6] Rouba, B. J., "Płótna jako podobrazia malarskie (Canvases as Painting Supports)", Ochrona Zabytków 3-4, 222244 (1985).

[7] Erhardt, D., Tumosa, C. S. and Mecklenburg, M. F., "Applying science to the question of museum climate", Museum microclimates: contributions to the Copenhagen conference, 11-18 (2007).

[8] Michalski, S., "Relative Humidity: A Discussion of Correct/Incorrect Values", Preprints of ICOM 10th Triennial Meeting, Vol. II, 624-629 (1993).

[9] Sutton, M., Orteu, J.-J. and Schreier, H., [Image correlation for shape, motion and deformation measurements], Springer, (2009).

[10] Targowski, P., Góra, M., Bajraszewski, T., Szkulmowski, M., Rouba, B., Łękawa-Wysłouch, T. and Tymińska, L., "Optical Coherence Tomography for Tracking Canvas Deformation", Laser Chemistry DOI: $10.1155 / 2006 / 93658,(2006)$.

[11] Dulieu-Barton, J. M., Dokos, L., Eastop, D., Lennard, F., Chambers, A. R. and Sahin, M., "Deformation and strain measurement techniques for the inspection of damage in works of art", Reviews in Conservation 6, 63-73 (2005).

[12] Debashis, M. and Young, C. R. T., "3D ESPI measurement of the strain fields introduced by strip-lining paintings", Proceedings of ICOM-CC Triennial Conference, 661 (2008).

[13] Tymińska-Widmer, L., Targowski, P., M., G., M., I., Łękawa-Wysłouch, T. and Rouba, B., "Optical Coherence Tomography - a Novel Tool for the Examination of Oil Paintings", Proceedings of Conservation Science 2007, 175-182 (2008).

[14] Malesa, M., Szczepanek, D., Kujawińska, M., Świercz, A. and Kołakowski, P., "Monitoring of Civil Engineering Structures Using DIC Technique", Book of Abstracts ICEM14, 31014 (2010).

[15] Orteu, J.-J., "3-D computer vision in experimental mechanics", Optics and Lasers in Engineering 47, 282-291 (2009).

[16] Dulieu-Barton, J. M., Khennouf, D., Chambers, A. R., Lennard, F. and Eastop, D., "Long term condition monitoring of tapestries using image correlation", Proceedings of the SEM Annual Conference, (2010).

[17] Khennouf, D., Dulieu-Barton, J. M., Chambers, A. R., Lennard, F. J. and D.D., E., "Assessing the Feasibility of Monitoring Strain in Historical Tapestries Using Digital Image Correlation", Strain 46, 19-32 (2010).

[18] Hartley, R. and A., Z., [Multiple View Geometry in computer vision], Cambridge University Press, Cambridge \& New York (2003). 